\title{
Current Perspective Concerning the Potential Value of Chloroplast Lipidome in Assessing Moss Response to Abiotic Stress During Boreal Forest Regeneration
}

\author{
Grace Callahan ${ }^{1 *}$, Xinbiao Zhu ${ }^{2}$ and Raymond H. Thomas ${ }^{1 *}$ \\ 'Environmental Science, Boreal Ecosystem Research Facility, Memorial University of Newfoundland - Grenfell Campus, \\ Corner Brook, NL, Canada, ${ }^{2}$ Natural Resources Canada, Canadian Forest Service-Atlantic Forestry Centre, Corner Brook, \\ NL, Canada
}

OPEN ACCESS

Edited by:

Guobao Xu,

Northwest Institute

of Eco-Environment and Resources

(CAS), China

Reviewed by:

Hu Bin,

University of Freiburg, Germany

$\operatorname{Bin} X u$,

Northern Alberta Institute of Technology (NAIT), Canada

*Correspondence:

Grace Callahan

gecallahan@grenfell.mun.ca

Raymond H. Thomas

rthomas@grenfell.mun.ca

Specialty section: This article was submitted to Temperate and Boreal Forests, a section of the journal Frontiers in Forests and Global Change

Received: 30 September 2021 Accepted: 26 January 2022 Published: 04 March 2022

Citation:

Callahan G, Zhu X and Thomas RH (2022) Current Perspective Concerning the Potential

Value of Chloroplast Lipidome

in Assessing Moss Response to Abiotic Stress During Boreal Forest

Regeneration.

Front. For. Glob. Change 5:786237. doi: 10.3389/ffgc.2022.786237
Mosses play important roles in the regulation of environmental or metabolic conditions in boreal forest ecosystems. Sphagnum and feathermoss are the two main bryophytes found in boreal forest understory. Clearcut harvesting (common method of boreal forest regeneration) can expose understory vegetation to water and light stress. Water and light stress can significantly impact moss growth during boreal forest regeneration. Analysis of the membrane lipidome, photosynthetic parameters and pigments can be very effective in assessing moss response to abiotic stress following clearcut harvesting. Although lipidomics is commonly used in environmental stress assessment of plants, application to assess moss lipidome and stress response is very limited. Bryophytes may alter or remodel their membrane lipid composition to acclimate or adapt to environmental stressors. Thus, this perspective provides insights into how moss lipids may serve as useful biomarkers of moss stress response or adaptation to environmental stress during boreal forest regeneration following clearcut harvesting.

Keywords: moss, membrane lipids, abiotic stress, clearcut harvesting, lipidomics

\section{HIGHLIGHTS}

- Moss plays key roles in regulating environmental conditions in the boreal forest.

- Clearcutting is a common harvesting method for regeneration of boreal forest stands.

- Following resource harvesting, below-canopy vegetation may be exposed to environmental stress, such as light and water stress.

- Moss may adapt to different light environments through alteration of photosynthetic cells and pigments.

- Alteration of membrane lipid composition may potentially allow mosses to adapt to unfavorable environmental conditions.

- Lipidomics has been used as a tool to assess abiotic and biotic stress in plants, however little information is available on moss lipidome and their contributions to moss acclimation to environmental stress.

- Evaluation of lipid composition in plants may allow for better understanding of the alteration of plant lipids in response to changes in environmental conditions. 


\section{INTRODUCTION}

Moss plays a key role in regulating environmental conditions in the boreal forest, such as soil climate, carbon cycling and forest regeneration. Sphagnum and feathermoss are common bryophytes within boreal black spruce (Picea mariana) forests. Clearcut harvesting is a common technique for regeneration of boreal forest stands that may expose understory vegetation to environmental stress following resource harvesting. Abiotic stress, such as water and light stress, can significantly impact moss growth during boreal forest regeneration. Light stress in plants can be evaluated through analysis of photosynthetic parameters and pigments. Lipidomics is the study of lipid compounds to determine structure and function in a cell or organism. Lipidomics has been used as a tool to assess abiotic and biotic stress in many plants, but very little information is available on moss lipidome and their contributions to moss acclimation to environmental stress. Plant adaptation to changing habitat conditions is crucial to maintain physiological function. Plants may alter or remodel their membrane lipid composition or metabolism to acclimate or adapt to stress. Therefore, lipids may serve as biomarkers of stress response to assess moss adaptation to environmental stress. This paper will provide insights into the effects of clearcut harvesting on moss photosynthetic adaptation, moss abiotic stress response to changing irradiance following clearcutting, and the importance of the membrane lipidome in assessing moss abiotic stress response during boreal forest regeneration.

\section{CHALLENGES AND RELEVANCE OF ASSESSING MOSS RESPONSE TO CLEARCUT HARVESTING}

\section{Challenges}

Clearcut harvesting represents a major anthropogenic disturbance in boreal forests following resource harvesting for the timber industry and may expose understory moss to environmental stressors such as water and light stress. There are gaps in the literature concerning the moss membrane lipidome and response to abiotic stress, specifically light and water stress. The membrane lipidome has been used as a sensitive biomarker to assess abiotic stress response in several plant species. Thus, there is interest in moss membrane lipids as a biomarker to assess moss response to abiotic stress. There is also significant interest in strategies for the sustainable regeneration of boreal forests following resource harvesting. However, it is unclear how clearcutting as a harvesting method affects moss response to environmental stress, including light and water stress.

\section{Relevance}

Evaluation of the moss lipidome could provide significant improvement in the current understanding of how moss membrane lipids vary with species, seasons, and response to environmental stressors as a determinant of their adaptation or survival to the stressor. For example, galactolipids such as monogalactosyldiacylglycerols (MGDG) are specific to the chloroplast and could be used to assess chloroplast function and effects on moss growth during acclimation to environmental stressors. Therefore, characterization of the moss lipidome can provide useful insights into how the moss lipidome can be used as an effective tool to assess moss metabolism, response or adaptation to abiotic stress following clearcut harvesting during boreal forest regeneration.

\section{BOREAL FORESTS AND CLEARCUT HARVESTING}

\section{Resource Harvesting and Forest Regeneration}

There are 347 million ha of forest in Canada, which accounts for $9 \%$ of forests in the world (Canadian Forest Services, Natural Resources Canada, 2018). The timber industry is an essential manufacturing sector and many wood-based products are produced, including softwood lumber, wood pulp, paper, newsprint and more (Canadian Forest Services, Natural Resources Canada, 2018). Less than 1\% of Canada's forests are harvested each year and nearly $80 \%$ of Canada's forests are boreal forests (Canadian Forest Services, Natural Resources Canada, 2018). Forest management systems must address ecological issues and ensure that forest regeneration standards are being met following timber production. Therefore, forest regeneration is of significant concern in tree harvesting methods (Canadian Forest Services, Natural Resources Canada, 2018). Forest regeneration strategies are necessary in order to regain productivity and restore functioning ecosystems following resource harvesting, or anthropogenic disturbance.

\section{Clearcut Harvesting; a Method of Forest Regeneration}

Clearcutting is a common harvesting practice for regeneration of boreal forest stands (Zhu et al., 2019). Clearcutting is considered a major anthropogenic disturbance and accounts for approximately $80 \%$ of boreal forests harvested annually in Canada (Youngblood and Titus, 1996). The objective of clearcutting as a harvesting method is the regeneration of a new even-aged stand through the removal of all tress in a forested area (Youngblood and Titus, 1996). When the clearcutting method is being applied, many factors are taken into account. Information must be gathered on site factors, species, crop tree characteristics, as well as successional pathways after disturbance (Youngblood and Titus, 1996).

\section{Effects of Harvesting on Understory Productivity and Nutrient Cycling}

Ecological processes must be considered in the regeneration of forests, including the impacts of harvesting on nutrient cycling and long-term productivity (Youngblood and Titus, 1996). Removal of trees in an area exposes the below-canopy microclimate. Thus, nutrient cycling associated with closed 
canopy forests will be influenced (Youngblood and Titus, 1996). The microclimate post-harvest is favorable for microbial activity; water table levels and soil moisture contents increase as there are declines in transpiration water loss (Youngblood and Titus, 1996). In addition, soil surface temperatures increase post-harvest (Youngblood and Titus, 1996). Forest floor photosynthesis is an important process in open canopies, as a significant amount of incoming radiation reaches ground vegetation (Bergeron et al., 2009). This process can therefore represent a significant portion of carbon $(C)$ assimilation in open canopy ecosystems, by which inorganic $\mathrm{C}$ is converted into forms of organic C (Bergeron et al., 2009). Forest floor productivity relies upon favorable conditions of light, temperature, and moisture (Bergeron et al., 2009).

\section{Carbon Balance in Ecosystems}

Boreal forest soils contain significant $\mathrm{C}$ reservoirs and are active sinks for terrestrial C (Harden et al., 1997). Decomposition of organic matter is limited by conditions such as short growing seasons, cold temperatures, and high moisture contents possibly inhibiting aerobic activities which are common features in the boreal biome (Harden et al., 1997). These conditions contribute to forest floor accumulations of C-rich material. C storage in northern or boreal soils is highly influenced by moisture content and soil drainage (Harden et al., 1997). Disturbances such as clearcut harvesting is a determining factor that can affect the uptake and release of $\mathrm{C}$ from boreal forest ecosystems (Gough et al., 2013).

Plant photosynthesis significantly influences $\mathrm{C}$ fluxes within ecosystems (Bonan, 1991). The exchange of C between the atmosphere and terrestrial ecosystems occurs through processes including photosynthesis and respiration (Bonan, 1991). Photosynthesis removes carbon dioxide $\left(\mathrm{CO}_{2}\right)$ from the atmosphere and emits $\mathrm{CO}_{2}$ through respiration (Bonan, 1991). Boreal forests are common net C sinks when they are undisturbed. This means that $\mathrm{C}$ uptake by photosynthesis outweighs $\mathrm{C}$ loss through respiration, hence a net $\mathrm{C}$ retention within the ecosystem (Bonan, 1991).

\section{PROPERTIES OF MOSSES IN BOREAL FORESTS}

\section{The Role of Mosses in Ecosystems}

Mosses are important parts of many ecosystems, specifically in boreal forests where they play an important role in regulating conditions such as soil climate, nitrogen $(\mathrm{N})$ assimilation, forest regeneration, and $\mathrm{C}$ cycling in ecosystems (Zhu et al., 2019). In fact, mosses contribute significantly to aboveground vegetative biomass, which affect ecosystem processes such as C cycling (Lindo and Gonzalez, 2010). A large source of $\mathrm{N}$ fixation in boreal forests comes from mosses in association with cyanobacteria. Below ground, mosses transform soil microclimates and alter rates of decomposition, which may influence forest regeneration (Lindo and Gonzalez, 2010). In addition, mosses form broad ground cover of forest floors and are able to collect surface elements such as particulate organic debris and atmospheric nutrients (Lindo and Gonzalez, 2010).

\section{Properties of Mosses}

Mosses are the dominant taxa within the bryophyte group, which also consists of liverworts and hornworts (Lindo and Gonzalez, 2010). Bryophytes generally colonize shaded habitats and possess traits of shade-adapted plants (Tobias and Niinemets, 2010). Mosses lack adaptations to control water use and are poikilohydric in nature. This means mosses are susceptible to drying, or desiccation, as moss water content depends on environmental moisture (Tobias and Niinemets, 2010). Due to their poikilohydric nature, mosses cannot maintain high water content during periods of high light intensity, therefore growth is favored in low light conditions (Tobias and Niinemets, 2010). In low light conditions, adequate water content can be maintained for active photosynthesis for longer periods of time (Tobias and Niinemets, 2010).

\section{Major Groups of Mosses in Boreal Forests}

Bryophytes commonly form dense ground cover in boreal black spruce (Picea mariana) forests (Bisbee et al., 2001). The main groups of bryophytes within boreal black spruce forests include Sphagnum and feathermoss (Bisbee et al., 2001). Figure 1 displays the moss groups Sphagnum and freathermoss, and the three feathermoss species Pleurozium schreberi, Hylocomium splendens, and Ptilium crista-castrensis. Both groups have different influences on ecosystem function and C accumulation. Sphagnum moss influences certain ecosystem processes more than feathermoss, such as increasing soil moisture content due to high water storage capacity and decreasing soil temperature (Bisbee et al., 2001). In addition, Sphagnum moss accumulates a much thicker and denser mat (Bisbee et al., 2001). Therefore, C accumulation in peat is generally greater in black spruce forests with Sphagnum dominated moss species (Bisbee et al., 2001).

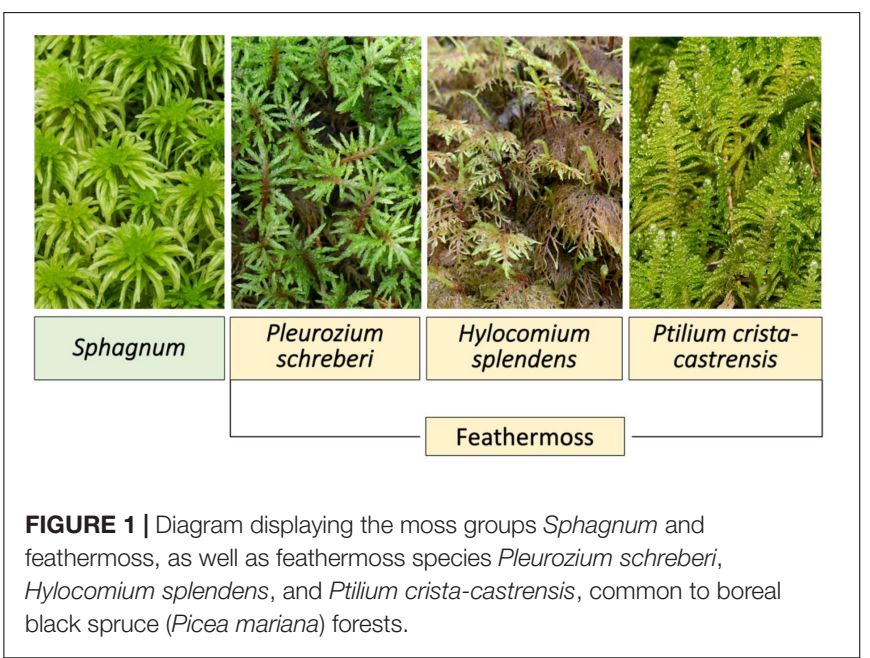




\section{Growth Properties of Feathermoss}

Pleurozium schreberi, Hylocomium splendens, and Ptilium crista-castrensis are three feathermosses common to boreal forests (Tobias and Niinemets, 2010). They account for greater than $60 \%$ of the ground layer in boreal forests of Canada (Benscoter and Vitt, 2007). P. schreberi is a dominant feathermoss species in boreal forests (Tobias and Niinemets, 2010). The shoots and branches of feathermosses $P$. schreberi and $P$. crista-castrensis grow both apically and laterally, extending the length of branches from previous year's growth (Tobias and Niinemets, 2010). Growth of H. splendens generally starts at a single point that branches from the main axis during spring and reaches full growth by the next fall (Okland and Okland, 1996). P. crista-castrensis has monopodial branching and a shoot that derives from the activity of a single apical cell (Pedersen et al., 2001). The shoot has a feather-like shape, as there are several lateral branches arranged pinnately (Pedersen et al., 2001).

\section{FACTORS INFLUENCING MOSS GROWTH}

Environmental factors that may affect moss growth include temperature, light, and water, which may show annual or seasonal variation (Skre et al., 1983). Water content is a significant factor limiting moss photosynthesis. Photosynthetic capacity of moss may be reduced following prolonged periods of desiccation. Light is another important factor limiting moss growth (Skre et al., 1983). Forest understories are characterized by their variable light conditions and moss species must adapt for survival in these habitats. Therefore, mosses may be subjected to periods of shade or periods of direct sunlight. Shaded areas with low light intensities are essential for moss growth. These conditions contribute to maintaining a positive photosynthetic rate (Skre et al., 1983). Light may also influence moss growth by increasing temperatures and rates of desiccation. Moisture limitations may be a determinant of moss growth under specific light intensities, as moss production may be increased in shaded areas and decreased in areas exposed to direct sunlight due to moisture limitations (Skre et al., 1983). Therefore, the interaction between light, moisture, and temperature may significantly affect moss growth in their environment.

Bryophytes have the capacity to recover photosynthesis upon rewetting following long periods of drought (Proctor, 1990). This photosynthetic recovery depends on the duration and severity of desiccation. Desiccation tolerance may change seasonally, and the limit of desiccation tolerance varies for each species (Proctor, 1990). Sphagnum mosses favor wet conditions for optimal growth (Kangas et al., 2014). Net photosynthesis of Sphagnum is related to moisture conditions, which corresponds with water table level (Kangas et al., 2014). Feathermosses also favor wet conditions for optimal growth, however, they have low abundance in water-saturated habitats. Their low abundance in these environments is a result of physiological constraints and competitive exclusion due to Sphagnum (Kangas et al., 2014). In wet conditions, Sphagnum species demonstrate higher growth rates than those in dry conditions. When comparing feathermoss productivity to Sphagnum, feathermoss species show lower productivity (Kangas et al., 2014).

\section{EFFECT OF CLEARCUT HARVESTING ON MOSS}

Forest bryophyte species can be indicative of microclimatic change (Arseneault et al., 2012). Following clearcut harvesting, mosses have been seen to decrease their ground layer cover and nutrient content (Nelson and Halpern, 2005). Bryophytes adapted to shade have limited capacity to recover from dry conditions over long periods of time (Nelson and Halpern, 2005). Species that survive the direct effects of clearcut harvesting may not be able to survive the post-harvest environment, which includes warm and dry conditions (Nelson and Halpern, 2005). Understanding the effects of harvesting on forest ground layer species is critical in its potential to recognize mosses as indicators of stress in boreal forests.

\section{MOSS RESPONSE TO ABIOTIC STRESS}

\section{Moss Photosynthetic, Mat Density, and Shoot Size Response}

Photosynthesis of moss is largely dependent on water availability (Wang and Bader, 2018). However, strategies for adapting photosynthesis to high and low water content may differ considerably between moss species (Wang and Bader, 2018). As moss dries out, photosynthesis is strongly reduced. However, photosynthesis can also be reduced in saturated moss. When mosses hold high amounts of water externally, the high diffusion resistance of water compared to air compromises the exchange of $\mathrm{CO}_{2}$ (Wang and Bader, 2018). As a result, photosynthesis is reduced. Considering that both lack and excess water content decrease photosynthesis, moss photosynthetic response to water content is optimal at a water content specific to species (Wang and Bader, 2018). In addition, water retention and holding capacities may also relate to maximum rates of photosynthesis. This is because architectural structures that affect water exchange may also affect the exchange of C (Wang and Bader, 2018).

Above ground net primary productivity in boreal forests has been found to increase with soil temperatures, as well as with mean air temperatures (Vogel et al., 2008). Warmer temperature and longer growing seasons may be a direct cause of increased net primary productivity. An indirect cause includes increased microbial activity with greater nutrient availability (Vogel et al., 2008). In moss species, maximum rates of net photosynthesis often show seasonal variation (Davey and Rothery, 1996). Photosynthetic rates often peak in the summer months. When temperatures decline in the colder months, metabolic activity becomes reduced (Davey and Rothery, 1996).

Mosses have the ability to extend periods of metabolic activity through close packing of shoots (Bates, 1988). When shoots are closely packed, it creates a smooth canopy that has a higher resistance to water loss through evaporation 
than individual shoots (Bates, 1988). In bryophyte colonies, density effects can be seen of density on shoot performance (Pedersen et al., 2001). Increased competition for resources, such as light, can result in negative effects on density dependence. Positive density dependence can be seen when there are microclimatic conditions that are favorable for growth (Pedersen et al., 2001). A positive relationship for growth is anticipated at low density, between shoot and biomass densities. When abiotic conditions are suboptimal, such as in moisture limited environments; bryophyte mean shoot performance peaks at an intermediate density (Pedersen et al., 2001). At intermediate density, the positive water retention effects of closely packed shoots are balanced with the negative effects of increased resource competition (Pedersen et al., 2001). This intermediate density within suboptimal abiotic conditions favors high growth of feathermosses. The relationship between feathermoss shoot size and density is commonly positive, although there may be some variability between species. Sphagnum moss often shows a negative relationship between shoot size and density (Pedersen et al., 2001).

Dense packing of shoots allows steep vertical light gradients within moss colonies, which forms a moss canopy (Pedersen et al., 2001). Increases in shoot size and density results in reduced light availability with increased depth of moss canopies (Tobias and Niinemets, 2010). Light gradients within moss canopies are associated with gradients of deterioration and decomposition. Therefore, the proportion of decomposing moss biomass becomes greater with increasing depth of moss canopy (Tobias and Niinemets, 2010). Concentrations of photosynthetic pigments, such as chlorophyll, have a tendency to decrease with reduced light availability in moss canopies (Tobias and Niinemets, 2010). A decrease of available light and increase of decomposition of moss biomass may cause photosynthetic pigments to concentrate in the upper portion of moss shoots (Tobias and Niinemets, 2010).

\section{Moss Response to Light Stress}

Plants can adapt to different light environments through growth and development of the whole plant, as well as through development of leaves, photosynthetic cells and pigments (Lichtenthaler et al., 2013). These light adaptations include structural and functional changes to the plant. Generally, light adaptations aim to optimize levels of photosynthesis (Lichtenthaler et al., 2013). When there is low available light, a series of compensatory mechanisms are activated, and include increasing the accumulation of photosynthetic pigments (Lichtenthaler et al., 2013). The function of photosynthetic pigments in plants is to absorb the required light energy for photosynthesis (Czeczuga, 1987). Therefore, by determining the concentration of photosynthetic pigments, we will gain a better understanding of photosynthetic response in plants to various environmental stresses. Chlorophylls and carotenoids are photosynthetic pigments that are abundant in most terrestrial plants. These pigments have an important role in photosynthesis and are used to construct pigment-protein complexes (Kume et al., 2018).

\section{Photosynthetic Pigments}

Chlorophylls are light-harvesting green pigments found in plants (Kume et al., 2018). There are two major forms; chlorophyll a (Chl $a$ ), which is the most abundant of all Chls, and chlorophyll b (Chl b), which is an accessory pigment (Lichtenthaler, 1987). Chl $a$ is found in the reaction centers of photosystems I and II, as well as in the light-harvesting pigment antenna of nearly all oxygenic photosynthetic organisms (Kume et al., 2018). Chl $b$ is only found in the pigment antenna (Lichtenthaler and Buschmann, 2001). In oxygenic photosynthetic organisms, Chl $b$ is considered the second most abundant chl. The ratio of Chl $a: b$ is a determinant of the photosynthetic light absorption efficiency, or the antenna size (Kume et al., 2018). However, different environmental and growth conditions may modify the $\mathrm{Chl} a: b$ ratio (Lichtenthaler, 1987). It has been suggested by some studies that shade-adapted plants contain larger chloroplasts and are more abundant in chlorophyll than plants in high light intensities (Boardman, 1977). Thus, the Chl $a: b$ ratio may adjust depending on the response of chlorophyll content in relation to level of light intensity (Boardman, 1977). Adaptation of the photosynthetic apparatus allows allocation of resources in order to achieve and maintain optimal photosynthetic rates (Beneragama and Goto, 2011).

Carotenoids are yellow, orange and red pigments in plants and are found in photosystem II, where they participate in the electron-transfer processes (Tracewell et al., 2001). Carotenoids can be divided into two distinct groups; carotenes, which are oxygen-free, and xanthophylls, which contain different forms of oxygen (Lichtenthaler, 1987). Carotenoid oxidation may play a role in photoprotection under light stress (Tracewell et al., 2001). The total carotenoid content in plant leaves may increase under low light intensities and may protect chlorophyll pigments from photodestruction (Czeczuga, 1987). The ratio of Chl $a$ and Chl $b$ to total carotenoid content is an indicator of plant "greenness" (Lichtenthaler and Buschmann, 2001).

By analyzing chlorophyll and carotenoid contents, as well as pigment ratios, we can evaluate plant stress of bryophytes (López and Carballeira, 1989). When species are able to acclimate to changing habitat conditions, it will likely give them a strategy for survival (Hájek et al., 2009). Through adaptations in pigment levels, plants can optimize light interception and utilization for photosynthetic functioning (Lichtenthaler et al., 2013). This acclimation response is common among vascular plants and has also been identified in bryophytes (Tobias and Niinemets, 2010). The photosynthetic pigment concentrations of mosses tend to decrease with increased light availability (Tobias and Niinemets, 2010). Whereas, in response to low light conditions, mosses increase photosynthetic pigment concentrations. The increase in pigment concentration enhances both light absorptance per unit mass and the harvesting of incident light (Tobias and Niinemets, 2010).

\section{Photosynthetic Parameters as a Measure of Photosynthesis}

Various parameters may be used to measure photosynthesis in plants. Photosynthetic parameters include photosynthesis light saturation point $\left(\mathrm{L}_{s}\right)$, dark respiration rate $\left(\mathrm{R}_{d}\right)$, net maximum 
photosynthetic rate $\left(\mathrm{P}_{\text {nmax }}\right)$, apparent quantum efficiency (AQE) and photosynthesis light compensation point $\left(\mathrm{L}_{c}\right)$ (Kangas et al., 2014). $\mathrm{L}_{s}$ is the point at which the photosynthetic rate is not increased by light intensity (Kangas et al., 2014). $\mathrm{L}_{c}$ is the point at which the photosynthetic rate is equivalent to the rate of respiration and is a measure of light-use efficiency at low light intensities. $\mathrm{R}_{d}$ is respiration in the absence of light, which involves the uptake of oxygen or production of $\mathrm{CO}_{2}$ (Kangas et al., 2014). $\mathrm{P}_{\text {nmax }}$ shows the maximum rate of light-saturated photosynthesis, as well as the photosynthetic capacity (Kangas et al., 2014). The AQE is a measure of photosynthetic efficiency and is expressed in moles of photons absorbed per mole of fixed $\mathrm{CO}_{2}$ or evolved $\mathrm{O}_{2}$ (Singsaas et al., 2001). Measurements of photosynthetic parameters can be done in the laboratory through portable photosynthesis systems for assessment of $\mathrm{CO}_{2}$ exchange and chlorophyll fluorescence (Kangas et al., 2014). These high precision instruments allow plant leaves to be placed in chambers for measurement of various photosynthetic parameters (Kangas et al., 2014). After collection of data, light response curves can be generated to illustrate variations in photosynthetic rate as a function of light (Evans et al., 1993). Light response curves provide information on the $\mathrm{P}_{\text {nmax }}, \mathrm{AQE}$, and $\mathrm{L}_{c}$ (Evans et al., 1993).

It was found that photosynthetic properties may differ between plants of different successional stages (Kangas et al., 2014). When plant physiological stress increases, parameters such as $\mathrm{P}_{\text {nmax }}, \mathrm{R}_{d}$, and $\mathrm{L}_{c}$ tend to decrease from early to late successional species (Kangas et al., 2014). One study found that feathermoss species had the lowest $\mathrm{L}_{c}$ of net photosynthesis and Sphagnum species had the highest, when determining moss adaptation to shady and moisture limited environments (Kangas et al., 2014). A similar trend was seen in terms of $\mathrm{P}_{n \max }, \mathrm{R}_{d}$ and net productivity, as feathermoss species had the lowest $\mathrm{P}_{\text {nmax }}, \mathrm{R}_{d}$ and net productivity and Sphagnum species had the highest. Due to the low $\mathrm{C}$ assimilation, $\mathrm{R}_{d}$ rates and $\mathrm{L}_{c}$ of feathermosses under shaded, dry conditions, they could be considered to be stresstolerant species through their adaptation (Kangas et al., 2014).

\section{Effect of Clearcut Harvesting on Moss Photosynthesis}

In a study by Zhu et al. (2019) the effects of clearcutting on moss species in harvested and forested plots were evaluated. The feathermosses Hylocomium and Pleurozium had the highest $\mathrm{P}_{\text {nmax }}$, Sphagnum had the lowest, and Ptilium was intermediate in forested plots (Zhu et al., 2019). Whereas in harvested plots, Sphagnum had the highest $\mathrm{P}_{\text {nmax }}$ and Pleurozium had the lowest. Feathermoss species showed decreased $\mathrm{L}_{c}$ and AQE in harvested plots compared to forested plots (Zhu et al., 2019). However, Hylocomium and Pleurozium showed increasing $\mathrm{L}_{s}$ in harvested plots compared to $\mathrm{L}_{s}$ in forested Hylocomium and Pleurozium (Zhu et al., 2019). The differences in photosynthetic properties between species in harvested and forested plots suggests that Sphagnum is more tolerant of desiccation and is able to maintain water content for efficient photosynthesis, particularly in unshaded environments such as those atypical following clearcut harvesting. In comparison, feathermosses may experience a decrease in photosynthetic capacity (Zhu et al., 2019).

\section{PLANT LIPIDS AND LIPIDOMICS}

Lipids are important compounds in cell membranes and have various functions (Yang and Han, 2016). Membranes in plants play important roles in structural function and plant processes (Tenenboim et al., 2016). Lipidomics is the discipline that studies lipid compounds through methods of analytical chemistry (Yang and Han, 2016). The lipidome refers to the entirety of lipids in a cell or organism, which may be analyzed to determine structure and function (Yang and Han, 2016). Metabolic processes such as photosynthesis or respiration occur on the membranes of specific organelles, such as chloroplasts (Tenenboim et al., 2016). Membranes contain specific lipid and protein composition, and this composition may be altered in response to environmental stress (Tenenboim et al., 2016). By evaluating lipid composition in moss, we may begin to understand the alteration of moss lipids in response to environmental stress. Considering membrane lipids are very dynamic and ultra-sensitive in response to environmental changes, lipidomics can provide superior information along with chlorophyll based assessment to give novel metabolic and phenotypic insights of how plants respond to environmental stress.

\section{Plant Membrane Lipids}

Lipids are composed of a hydrophilic polar head that is attached to a glycerol backbone and a hydrophobic tail with two fatty acids (Reszczyńska and Hanaka, 2020). Fatty acids are important building blocks of lipids and the aliphatic chain in lipids can be made of saturated fatty acids (SFA), unsaturated fatty acids (UFA), monounsaturated fatty acids (MUFA), or polyunsaturated fatty acids (PUFA), depending on the number of single or double bonds (Reszczyńska and Hanaka, 2020). The three main classes of lipids in plant membranes are glycerolipids, sphingolipids, and sterols. Each class of lipids contain different molecular species. Glycerolipids are the most abundant and are separated into four groups: phospholipids, galactolipids, triacylglycerols, and sulfolipids. Phospholipids are major membrane lipids in plants and contain a phosphorous moiety and head group attached to C3 and two fatty acids at C1 and C2, respectively of the glycerol moiety. This can lead to several subclasses of phospholipids varying in head group and fatty acid composition with different chain length and degree of unsaturation (Reszczyńska and Hanaka, 2020). The different classes of phospholipids include phosphatidylcholine (PC), phosphatidic acid (PA), phosphatidyl-ethanolamine (PE), phosphatidylserine (PS), phosphatidylinositol (PI), and phosphatidylglycerol (PG). Galactolipids are lipids that make up photosynthetic membranes and have two main classes; monogalactosyldiacylglycerol (MGDG) and digalactosyldiacylglycerol (DGDG). Other classes of glycerolipids are the sulfolipid sulfoquinovosyldiacylglycerol (SQDG), and triacylglycerols. The three glycerolipids MGDG, DGDG, and SQDG are synthesized exclusively in chloroplasts. In higher plants, the thylakoid membrane 
consists of MGDG, DGDG, SQDG and the phospholipid PG (Reszczyńska and Hanaka, 2020). This is illustrated in Figure 2, along with the photosynthetic pathway. Alterations in the content of these chloroplast lipids may influence properties of photosynthetic membranes and therefore may play a role in photosynthetic stress response.

\section{Plant Lipids as Biomarkers of Environmental Stress}

Plants are exposed to stress regularly in their growth environments (Reszczyńska and Hanaka, 2020). Adaptation to changing habitat conditions is critical to maintain physiological function, and for ultimate survival. Plants may alter lipid and protein content to survive in unfavorable environments (Reszczyńska and Hanaka, 2020). Sensitivity to conditions, such as temperature change, can cause changes in lipid composition. In fact, plants are known to remodel their membrane lipid composition as a natural adaptation or acclimation response to various biotic and abiotic stressors. Aside from the influence of lipid function on properties of membranes, lipids are essential components of the protein complexes in the electron transport chain of photosynthesis (Reszczyńska and Hanaka, 2020). Studies have determined that membrane lipid composition
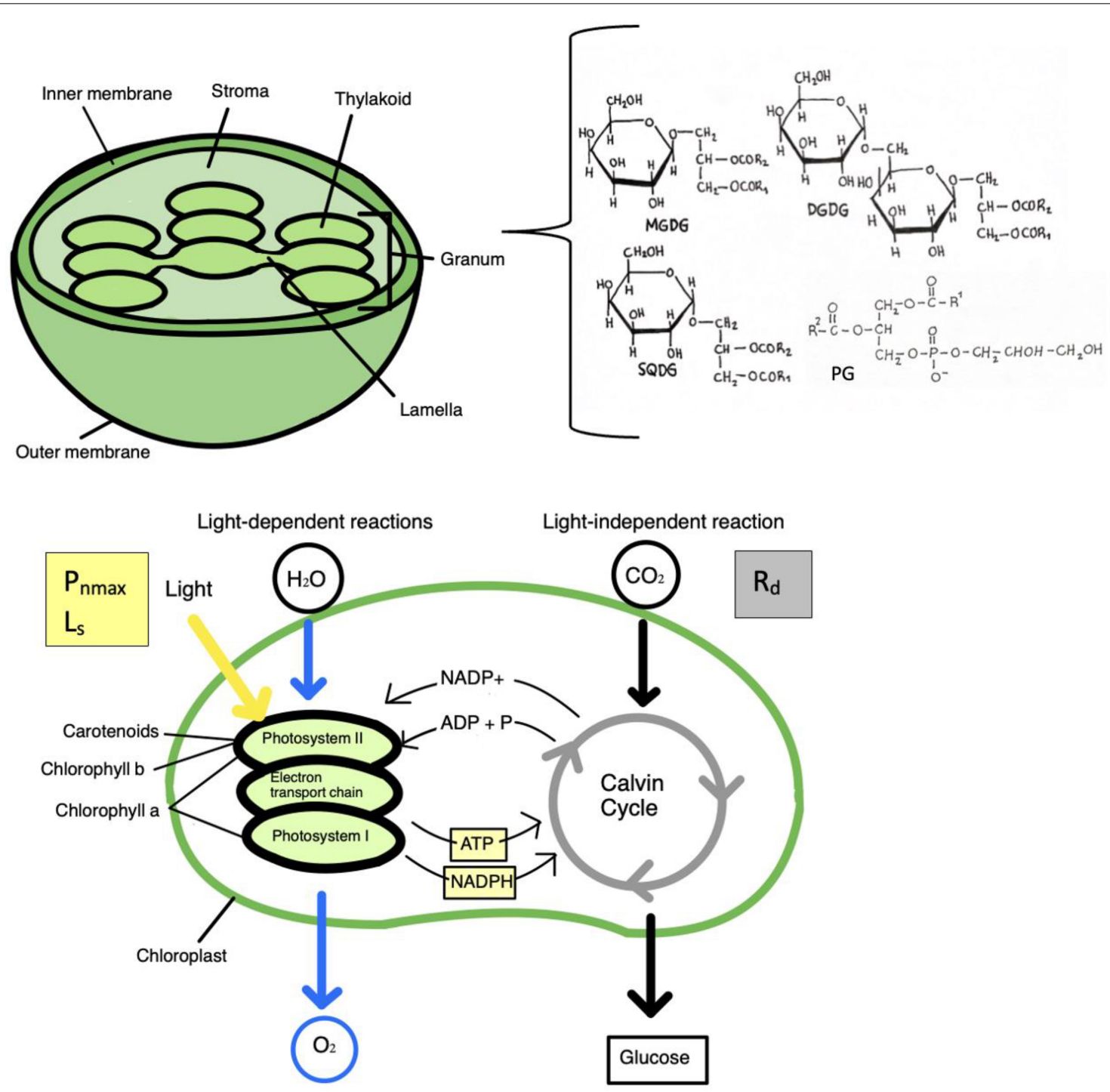

FIGURE 2 | The three glycerolipids monogalactosyldiacylglycerol (MGDG), digalactosyl diacylglycerol (DGDG), and sulfoquinovosyldiacylglycerol (SQDG), are found exclusively in the chloroplast membrane, and in higher plants, the thylakoid membrane consists of MGDG, DGDG, SQDG and phosphatidylglycerol (PG). Alterations in the content of these lipids could impact properties of photosynthetic membranes. Therefore, these glycerolipids may play a role in photosynthetic stress response. The photosynthetic pathway is illustrated, with the light dependent and independent (dark) reactions. Chlorophyll $a$ is found in the reaction centers of photosystems and II, while chlorophyll $b$ and carotenoids are accessory pigments in the pigment antenna. Photosynthetic parameters are a measure of photosynthesis.

Photosynthesis light saturation point $\left(L_{S}\right)$ and net maximum photosynthetic rate $\left(P_{n \max }\right)$ are a measure of light-saturated photosynthesis, while dark respiration rate $\left(R_{d}\right)$ is respiration in the absence of light. 
may be influenced by abiotic stress, such as temperature, light, nutrient deficiency, salinity and drought. Lipid composition was dependent on the length of time for which the plant was subjected to stress (Reszczyńska and Hanaka, 2020). There is also variation in the observed trends of lipid composition in response to stress. For example, the total amount of each lipid class may increase, or specific fatty acids may decrease (Reszczyńska and Hanaka, 2020). Overall, response of lipid composition depends on the environmental stress of concern. Therefore, lipids may serve as biomarkers of stress response in the context of plant adaptation to different environmental stressors.

Several studies have evaluated the effects of plant exposure to abiotic stress (Tenenboim et al., 2016). Plants often exhibited changes in regulation, degradation, synthesis, or restructuring of lipids due to stress exposure (Tenenboim et al., 2016). A result of temperature fluctuation are changes in membrane lipid content. These changes were an effort to maintain physical membrane properties of the plant (Tenenboim et al., 2016). Another abiotic stressor that influences plant membrane lipids is hypoxia (lack of oxygen in environment). Hypoxia in plants is often caused by submergence in water or flooding (Tenenboim et al., 2016). After plant exposure to hypoxic conditions, lipidomics analysis identified an increase in ceramides (class of sphingolipids) (Tenenboim et al., 2016). This increase in ceramides may be an attempt for the plant to remodel its membrane composition as a response to tolerate the hypoxic conditions.

There are fewer lipidomic studies conducted to assess plant response to biotic stress, compared to studies for abiotic stress (Tenenboim et al., 2016). Considering biotic stress is caused by living organisms, lipids have various functions in protecting plants affected by other organisms. These include acting as components of mechanical barriers and signaling molecules in plant immunity (Tenenboim et al., 2016). Lipids may also act as antimicrobial compounds. These functions are important in defense against biotic stress, such as stress due to herbivore or pathogen attacks (Tenenboim et al., 2016).

\section{Importance of Galactolipids in Photosynthetic Membranes}

The major structural components of photosynthetic membranes are the galactolipids MGDG and DGDG (Wang et al., 2020). More specifically, MGDG and DGDG account for approximately $80 \%$ of total lipids in chloroplast and thylakoid membranes (Wang et al., 2020). The sulfolipid SQDG occurs to a lesser extent than MGDG and DGDG in plants, but are also found exclusively in the chloroplast membrane. Several studies have found MGDG to be present in photosystem I and photosystem II, while DGDG is only present in photosystem II ( $\mathrm{Li}$ and $\mathrm{Yu}, 2018$ ). Both MGDG and DGDG are essential for several aspects of the photosynthetic light reaction ( $\mathrm{Li}$ and $\mathrm{Yu}, 2018$ ). Alterations of MGDG and DGDG content could impact biophysical properties of photosynthetic membranes (Wang et al., 2020). Therefore, these two classes of galactolipids may contribute significantly to photosynthetic stress response. When plants are subjected to stress, DGDG content, as well as the MGDG to DGDG ratio, tends to increase. These increases are to stabilize the chloroplast membrane in response to stress (Wang et al., 2020). Galactolipids are becoming an important area of research in terms of their role in adaptation mechanisms of plant photosynthesis, as well as in terms of their composition in response to stress (Wang et al., 2020).

\section{Plant Membrane Lipids Response to Drought Stress}

The galactolipids MGDG and DGDG have shown importance in plant tolerance to abiotic stress ( $\mathrm{Li}$ and $\mathrm{Yu}, 2018$ ). Several plant species during drought have hydrolyzed MGDG and reduced MGDG to DGDG ratio ( $\mathrm{Li}$ and Yu, 2018). It has been suggested that these changes in lipid composition may maintain stability of chloroplast membranes in response to drought stress ( $\mathrm{Li}$ and $\mathrm{Yu}, 2018)$. The lipidome of thyme plants sensitive and tolerant to drought stress has been evaluated and the lipid composition was found to be greatly altered by water deficiency (Moradi et al., 2017). In drought sensitive plants, both MGDG and DGDG, as well as phospholipids were observed to decrease (Moradi et al., 2017). Galactolipids are important structural components of the chloroplast including stroma lamellae and the grana system (Moradi et al., 2017). Reaction centers can be damaged when there is water deficiency in plants, and this may inhibit photosynthesis (Moradi et al., 2017). Previous studies have recognized that a trait of sensitive plants under drought stress is decreased galactolipid levels (Moradi et al., 2017). In terms of stress tolerant plants, there was an increase in galactolipids and unsaturated fatty acids in response to severe water deficiency. These increases may be an adaptation response by the plant to circumvent the adverse effects induced by drought stress (Moradi et al., 2017). Conversely, SQDG levels were reported to increase in drought tolerant wheat varieties, but decrease in drought sensitive plants (Taran et al., 2000).

\section{Relationship of Plant Membrane Lipids to Light Stress and Photosynthesis}

A study by Burgos et al. (2011) analyzed the changes of the glycerolipidome of Arabidopsis thaliana plants in response to different temperatures and light levels. Membrane fluidity is known to be reduced in response to lower temperatures, but increased when temperatures are higher (Burgos et al., 2011). Temperature changes involves changes in membrane permeability. In response to these changes, plants regulate the saturation levels of membrane glycerolipids (Burgos et al., 2011). Furthermore, the levels of phospholipid PC and galactolipid MGDG were reported to be increased in leaves of plants grown in cold temperatures (Burgos et al., 2011). Lipid metabolism is sensitive to both darkness and high light intensities (Burgos et al., 2011). Significant changes were found at high temperature, where PG unsaturated species decreased in response to increased temperature. It was suggested that these lipid changes may be related to plant membrane adaptation to heat stress (Burgos et al., 2011). It was determined that significant changes in the lipid 
composition occurred with changes in both temperature and light, as opposed to just temperature change (Burgos et al., 2011).

Research studies have established the presence of chloroplast lipids in photosynthetic membranes, however, few studies have evaluated the response of chloroplast lipids to light stress and how this may influence photosynthesis. When there are changes in content of chloroplast membrane lipids and unsaturated fatty acids, chloroplast and thylakoid membrane structure will be impacted ( $\mathrm{Li}$ et al., 2020). Chloroplast damage tends to decrease net photosynthetic rate and delay plant growth. Under unfavorable conditions, maintaining chloroplast structural stability and minimizing damage of chloroplasts may contribute significantly to plant resistance to environmental stress (Li et al., 2020). Plants may resist abiotic stress and maintain membrane stability and function through changes in lipid composition. Specifically, alterations in the DGDG to MGDG ratio could modify chloroplast membrane stability (Li et al., 2020). Therefore, changes in lipid content in response to abiotic stress, such as light stress, could provide an adaptation strategy for plants under adverse conditions. Changes in lipid composition may not only protect chloroplast membranes, but may also help to maintain efficient photosynthesis in plants.

Figure 3 illustrates the potential response of moss to abiotic stress following clearcutting. As previously discussed, light and water stress are two important abiotic stresses that may significantly impact moss growth. Moss may adapt to different light environments through alteration of photosynthetic cells and pigments including chlorophyll and carotenoids. Dense packing of shoots may allow retention of water, which is beneficial in water limited environments. In addition, alteration of membrane lipid composition may potentially allow mosses to adapt to unfavorable conditions. However, there is little information available on the moss membrane lipidome and response of membrane lipids to abiotic stress.

\section{Characterization of Moss Membrane Lipids and Current Status of Literature}

While there is sufficient research on plant lipids in response to environmental stress, very little research has been done concerning how the moss lipidome is remodeled in response

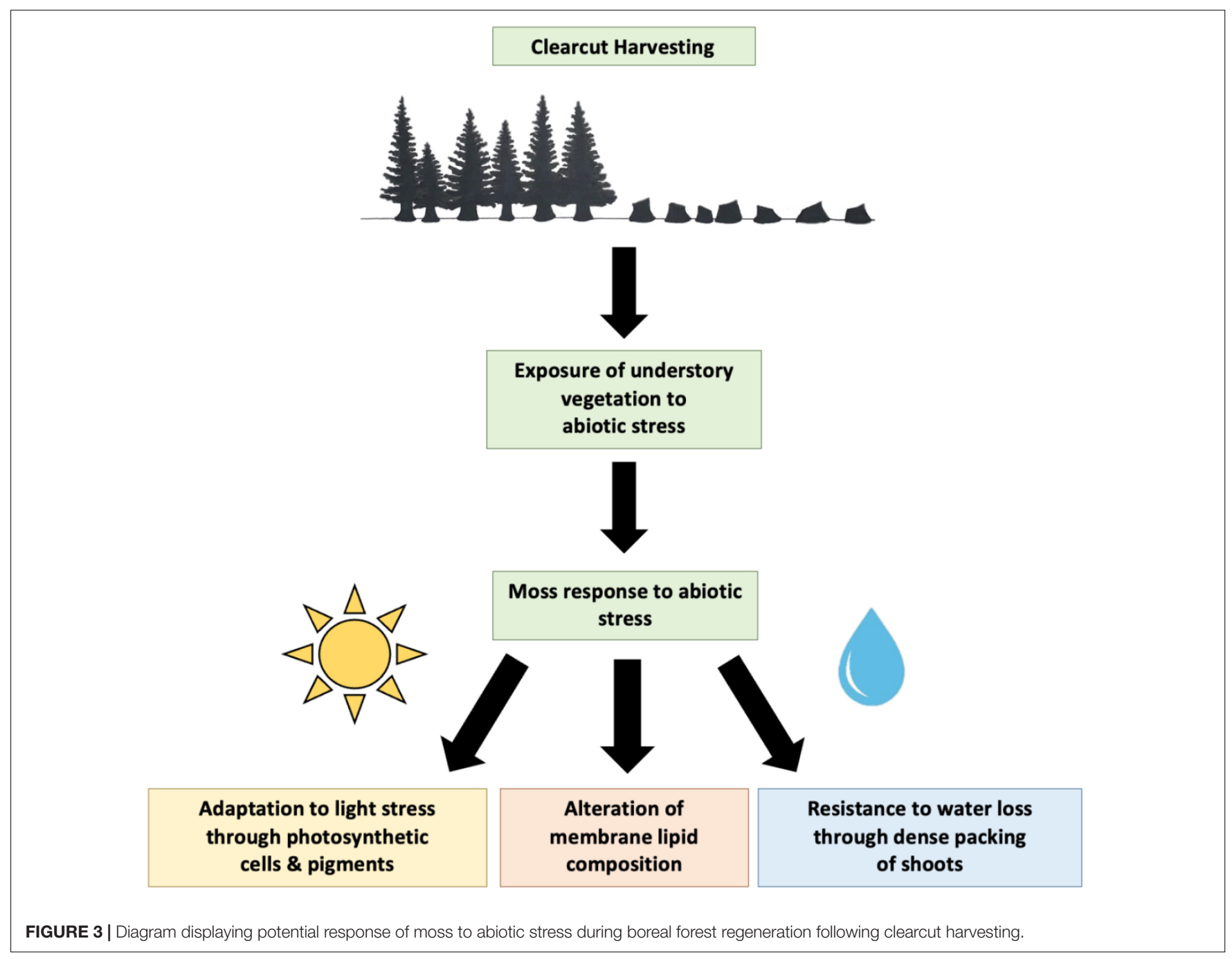


to abiotic stressors. As such, research concerning the lipid composition of bryophytes remains limited (Resemann et al., 2019). Much of the current published work in the literature focuses largely on primary lipid compounds, such as fatty acids, with a few looking at intact lipids such as phospholipids (Resemann et al., 2019).

For example, the majority of lipids detected in Sphagnum fallax were phospholipid species enriched with polyunsaturated long-chain fatty acids (Fudyma et al., 2019). Studies have reported significant levels of glycolipids, sphingolipids, phospholipids, and sterols in Sphagnum sp. (Fudyma et al., 2019). However, very little work is available in the scientific literature concerning how moss remodel their membrane lipidome during acclimation to environmental stress. A more in-depth understanding of moss lipid composition is needed to evaluate the response of moss membrane lipids to environmental stress, and more specifically, the response of moss chloroplast lipids to light and water stress.

\section{CONCLUSION}

Mosses plays important roles in maintaining boreal forest ecosystems and their photosynthetic processes can determines survival and effective response or acclimation when exposed to varying environmental stressors. Clearcut harvesting is a common sustainable boreal forest regeneration technique practiced to improve forest stands following resource harvesting. Recent findings suggest clearcut harvesting appears to expose mosses in the forest understory to light and water stress, affecting their growth and survival. However, our understanding is limited concerning how clearcutting induces water and light stress and the strategies moss employ metabolically to circumvent these stressors. This perspective presents insights on how lipidomics

\section{REFERENCES}

Arseneault, J., Fenton, N. J., and Bergeron, Y. (2012). Effects of variable canopy retention harvest on epixylic bryophytes in boreal black spruce-feathermoss forests. Can. J. For. Res. 42, 1467-1476. doi: 10.1139/X2012-054

Bates, J. W. (1988). The effect of shoot spacing on the growth and branch development of the moss Rhytidiadelphus triquetrus. New Phytol. 109, 499-504. doi: 10.1111/j.1469-8137.1988.tb03726.x

Beneragama, C. K., and Goto, K. (2011). Chlorophyll a: b ratio increases under low-light in 'shade-tolerant' Euglena gracilis. Trop. Agric. Res. 22, 12-25. doi: 10.4038/tar.v22i1.2666

Benscoter, B. W., and Vitt, D. H. (2007). Evaluating feathermoss growth: a challenge to traditional methods and implications for the boreal carbon budget. J. Ecol. 95, 151-158. doi: 10.1111/j.1365-2745.2006.01180.x

Bergeron, O., Margolis, H. A., and Coursolle, C. (2009). Forest floor carbon exchange of a boreal black spruce forest in eastern North America. Biogeosciences 6, 1849-1864. doi: 10.5194/bg-6-1849-2009

Bisbee, K. E., Gower, S. T., Norman, J. M., and Nordheim, E. V. (2001). Environmental controls on ground cover species composition and productivity in a boreal black spruce forest. Oecologia 129, 261-270. doi: 10.1007/ s004420100719

Boardman, N. K. (1977). Comparative photosynthesis of sun and shade plants. Annu. Rev. Plant Physiol. 28, 355-377. doi: 10.1146/annurev.pp.28.060177. 002035 can be applied as an effective biochemical tool to assess the moss lipidome, metabolic response, and adaptation or acclimation to light and water stress induced by clearcut harvesting during boreal forest regeneration. We hope this perspective will stimulate more work in the scientific community applying lipidomics or lipid bioinformatics as an effective biochemical tool to improve our understanding of how clearcut harvesting induced environmental stress on moss in the forest understory. Specifically, how the effects of clearcut harvesting influence moss metabolic response determining unsuccessful or successful survival and acclimation or adaptation to abiotic stress during boreal forest regeneration.

\section{DATA AVAILABILITY STATEMENT}

The original contributions presented in the study are included in the article/supplementary material, further inquiries can be directed to the corresponding author/s.

\section{AUTHOR CONTRIBUTIONS}

RT and XZ conceptualized the research. GC prepared original manuscript draft. RT supervised the research. All authors contributed to manuscript revision, read, and approved the submitted version.

\section{FUNDING}

This work was supported by the Natural Sciences and Engineering Research Council of Canada. Undergraduate Student Research Awards (NSERC USRA; Grant No. RGPIN/004464-2016).

Bonan, G. B. (1991). Seasonal and annual carbon fluxes in a boreal forest landscape. J. Geophys. Res. Atmospheres 96, 17329-17338. doi: 10.1029/91JD01923

Burgos, A., Szymanski, J., Seiwert, B., Degenkolbe, T., Hannah, M. A., Giavalisco, P., et al. (2011). Analysis of short-term changes in the Arabidopsis thaliana glycerolipidome in response to temperature and light. Plant J. 66, 656-668. doi: 10.1111/j.1365-313X.2011.04531.x

Canadian Forest Services, Natural Resources Canada (2018). The State of Canada's Forests. Annual Report 2018. Available online at: https://cfs.nrcan.gc.ca/ pubwarehouse/pdfs/39336.pdf (accessed October 20, 2020).

Czeczuga, B. (1987). Carotenoid contents in leaves grown under various light intensities. Biochem. Syst. Ecol. 15, 523-527. doi: 10.1016/0305-1978(87) 90098-6

Davey, M. C., and Rothery, P. (1996). Seasonal variation in respiratory and photosynthetic parameters in three mosses from the Maritime Antarctic. Ann. Bot. 78, 719-728. doi: 10.1006/anbo.1996.0182

Evans, J. R., Jakobsen, I., and Ögren, E. (1993). Photosynthetic light-response curves. Planta 189, 191-200. doi: 10.1007/BF00195075

Fudyma, J. D., Lyon, J., AminiTabrizi, R., Gieschen, H., Chu, R. K., Hoyt, D. W., et al. (2019). Untargeted metabolomic profiling of Sphagnum fallax reveals novel antimicrobial metabolites. Plant Direct 3:e00179. doi: 10.1002/pld3.179

Gough, C. M., Hardiman, B. S., Nave, L. E., Bohrer, G., Maurer, K. D., Vogel, C. S., et al. (2013). Sustained carbon uptake and storage following moderate disturbance in a Great Lakes forest. Ecol. Appl. 23, 1202-1215. doi: 10.1890/121554.1 
Hájek, T., Tuittila, E., Ilomets, M., and Laiho, R. (2009). Light response of mire mosses- a key to survival after water-level drawdown? OIKOS 118, 240-250. doi: 10.1111/j.1600-0706.2008.16528.x

Harden, J. W., O'Neill, K. P., Trumbore, S. E., Veldhuis, H., and Stocks, B. J. (1997). Moss and soil contributions to the annual net carbon flux of a maturing boreal forest. J. Geophys. Res. 102, 28805-28816. doi: 10.1029/97jd02237

Kangas, L., Maanavilja, L., Hájek, T., Juurola, E., Chimner, R. A., Mehtätalo, L., et al. (2014). Photosynthetic traits of Sphagnum and feather moss species in undrained, drained and rewetted boreal spruce swamp forests. Ecol. Evol. 4, 381-396. doi: 10.1002/ece3.939

Kume, A., Akitsu, T., and Nasahara, K. N. (2018). Why is chlorophyll b only used in light-harvesting systems? J. Plant Res. 131, 961-972. doi: 10.1007/s10265-0181052-7

Li, H., and Yu, C. (2018). Chloroplast galactolipids: the link between photosynthesis, chloroplast shape, jasmonates, phosphate starvation and freezing tolerance. Plant Cell Physiol. 59, 1128-1134. doi: 10.1093/pcp/pcy088

Li, J., Liu, L., Meng, Q., Fan, H., and Sui, N. (2020). The roles of chloroplast membrane lipids in abiotic stress responses. Plant Signal. Behav. 15:e1807152. doi: 10.1080/15592324.2020.1807152

Lichtenthaler, H. K. (1987). [34] Chlorophylls and carotenoids: pigments of photosynthetic biomembranes. Methods Enzymol. 148, 350-382. doi: 10.1016/ 0076-6879(87)48036- 1

Lichtenthaler, H. K., and Buschmann, C. (2001). "Chlorophylls and carotenoids: measurement and characterization by UV-VIS spectroscopy," in Current Protocols in Food Analytical Chemistry, eds R. E. Wrolstad, T. E. Acree, H. An, E. A. Decker, M. H. Penner, D. S. Reid, et al. (New York, NY: John Wiley and Sons), F4.3.1-F4.3.8. doi: 10.1002/0471142913.faf0403s01

Lichtenthaler, H. K., Babani, F., Navrátil, M., and Buschmann, C. (2013). Chlorophyll fluorescence kinetics, photosynthetic activity, and pigment composition of blue-shade and half-shade leaves as compared to sun and shade leaves of different trees. Photosynth. Res. 117, 355-366. doi: 10.1007/s11120013-9834-1

Lindo, Z., and Gonzalez, A. (2010). The bryosphere: an integral and influential component of the Earth's biosphere. Ecosystems 13, 612-627. doi: 10.1007/ s10021-010-9336-3

López, J., and Carballeira, A. (1989). A comparative study of pigment contents and response to stress in five species of aquatic bryophytes. Lindbergia 15, 188-194.

Moradi, P., Mahdavi, A., Khoshkam, M., and Iriti, M. (2017). Lipidomics unravels the role of leaf lipids in thyme plant response to drought stress. Int. J. Mol. Sci. 18:2067. doi: 10.3390/ijms18102067

Nelson, C. R., and Halpern, C. B. (2005). Short-term effects of timber harvest and forest edges on ground-layer mosses and liverworts. Can. J. Bot. 83, 610-620. doi: 10.1139/b05-036

Okland, R. H., and Okland, T. (1996). Population biology of the clonal moss hylocomium splendens in Norwegian boreal spruce forests. II. effects of density. J. Ecol. 84, 63-69. doi: 10.2307/2261700

Pedersen, B., Hanslin, H. M., and Bakken, S. (2001). Testing for positive densitydependent performance in four bryophyte species. Ecology 82, 70-88. doi: 10. 2307/2680087

Proctor, M. C. (1990). The physiological basis of bryophyte production. Bot. J. Linn. Soc. 104, 61-77. doi: 10.1111/j.1095-8339.1990.tb02211.x

Resemann, H. C., Lewandowska, M., Gömann, J., and Feussner, I. (2019). Membrane lipids, waxes and oxylipins in the moss model organism. Plant Cell Physiol. 60, 1166-1175. doi: 10.1093/pcp/pcz006

Reszczyńska, E., and Hanaka, A. (2020). Lipids composition in plant membranes. Cell Biochem. Biophys. 78, 401-414. doi: 10.1007/s12013-020-00947-w
Singsaas, E. L., Ort, D. R., and DeLucia, E. H. (2001). Variation in measured values of photosynthetic quantum yield in ecophysiological studies. Oecologia 128, 15-23. doi: 10.1007/s004420000624

Skre, O., Oechel, W. C., and Miller, P. M. (1983). Moss leaf water content and solar radiation at the moss surface in a mature black spruce forest in central Alaska. Can. J. For. Res. 13, 860-868. doi: 10.1139/x83-116

Taran, N., Okanenko, A., and Musienko, N. (2000). Sulpholipid reflects plant resistance to stress-factor action. Biochem. Soc. Trans. 28, 922-924. doi: 10.1042/ BST0280922

Tenenboim, H., Burgos, A., Willmitzer, L., and Brotman, Y. (2016). Using lipidomics for expanding the knowledge on lipid metabolism in plants. Biochimie 130, 91-96. doi: 10.1016/j.biochi.2016.06.004

Tobias, M., and Niinemets, Ü. (2010). Acclimation of photosynthetic characteristics of the moss pleurozium schreberi to among-habitat and within-canopy light gradients. Plant Biol. 12, 743-754. doi: 10.1111/j.14388677.2009.00285.x

Tracewell, C. A., Vrettos, J. S., Bautista, J. A., Frank, H. A., and Brudvig, G. W. (2001). Carotenoid photooxidation in photosystem II. Arch. Biochem. Biophys. 385, 61-69. doi: 10.1006/abbi.2000.2150

Vogel, J. G., Bond-Lamberty, B. P., Schuur, E. A., Gower, S. T., Mack, M. C., O'Connell, K. B., et al. (2008). Carbon allocation in boreal black spruce forests across regions varying in soil temperature and precipitation. Glob. Change Biol. 14, 1503-1516. doi: 10.1111/j.1365-2486.2008. 01600.x

Wang, Y., Zhang, X., Huang, G., Feng, F., Liu, X., Guo, R., et al. (2020). Dynamic changes in membrane lipid composition of leaves of winter wheat seedlings in response to PEG-induced water stress. BMC Plant Biol. 20:84. doi: 10.1186/ s12870-020-2257-1

Wang, Z., and Bader, M. Y. (2018). Associations between shoot-level water relations and photosynthetic responses to water and light in 12 moss species. AoB PLANTS 10:ly034. doi: 10.1093/aobpla/ply034

Yang, K., and Han, X. (2016). Lipidomics: techniques, applications, and outcomes related to biomedical sciences. Trends Biochem. Sci. 41, 954-969. doi: 10.1016/j. tibs.2016.08.010

Youngblood, A., and Titus, B. (1996). Clearcutting-a regeneration method in the boreal forest. For. Chronicle 72, 31-36. doi: 10.5558/tfc72031-1

Zhu, X., Nimmo, V., Jianghua, W., and Thomas, R. (2019). Sphagnum outcompetes feathermosses in their photosynthetic adaptation to postharvest black spruce forests. Botany 97, 585-597. doi: 10.1139/cjb-20190076

Conflict of Interest: The authors declare that the research was conducted in the absence of any commercial or financial relationships that could be construed as a potential conflict of interest.

Publisher's Note: All claims expressed in this article are solely those of the authors and do not necessarily represent those of their affiliated organizations, or those of the publisher, the editors and the reviewers. Any product that may be evaluated in this article, or claim that may be made by its manufacturer, is not guaranteed or endorsed by the publisher.

Copyright (c) 2022 Callahan, Zhu and Thomas. This is an open-access article distributed under the terms of the Creative Commons Attribution License (CC BY). The use, distribution or reproduction in other forums is permitted, provided the original author(s) and the copyright owner(s) are credited and that the original publication in this journal is cited, in accordance with accepted academic practice. No use, distribution or reproduction is permitted which does not comply with these terms. 